\title{
Distribuição e conservação de peixes anuais (Cyprinodontiformes: Rivulidae) no município do Chuí, sul do Brasil
}

\author{
Matheus Vieira Volcan ${ }^{1 *}$ \\ Luis Esteban Krause Lanés ${ }^{1}$ \\ Morevy Moreira Cheffe ${ }^{2}$ \\ Instituto Pró-Pampa, Laboratório de Ictiologia \\ Rua Gomes Carneiro 1043, CEP 96010-610, Pelotas-RS, Brasil \\ ${ }^{2}$ Grupo Especial de Estudos e Proteção ao Ambiente Aquático do Rio Grande do Sul \\ Setor de Ictiologia, Divisão de Fauna \\ Rua Tiradentes, 2247, CEP 96010-165, Pelotas-RS, Brasil \\ *Autor para correspondência \\ matheusvolcan@hotmail.com
}

Submetido em 30/03/2010

Aceito para publicação em 27/08/2010

\section{Resumo}

Este estudo baseia-se em levantamentos de campo realizados no período de agosto de 2004 a junho de 2009, objetivando a divulgação de dados sobre a ocorrência, distribuição e conservação de peixes anuais no município do Chuí. Quatro espécies foram registradas: Austrolebias charrua Costa e Cheffe, Austrolebias luteoflammulatus (Vaz-Ferreira, Sierra-de-Soriano e Scaglia-de-Paulete), Austrolebias prognathus (Amato) e Cynopoecilus melanotaenia (Regan), capturados em 14 diferentes pontos amostrais, distribuídos nas várzeas dos arroios Chuí e São Miguel, e marginais à estrada da Barra do Chuí. Todos os locais onde foram registradas populações de peixes anuais no Chuí estavam alterados por alguma forma de atividade antrópica, advinda principalmente da cultura do arroz e do pisoteio do gado. A principal área de ocorrência de anuais no município, e a de maior relevância para a conservação, está localizada nas várzeas do arroio Chuí.

Unitermos: área úmida, Austrolebias, peixes ameaçados, unidade de conservação

\section{Abstract}

Distribution and conservation of annual fishes (Cyprinodontiformes: Rivulidae) in the municipality of Chuí, southern Brazil. This study is based on captures of annual fishes conducted from August 2004 to June 2009 , aiming at the dissemination of data on their occurrence, distribution and conservation in the municipality of Chuí. Four species were recorded: Austrolebias charrua Costa e Cheffe, Austrolebias luteoflammulatus (Vaz-Ferreira, Sierra-de-Soriano e Scaglia-de-Paulete), Austrolebias prognathus (Amato) and Cynopoecilus melanotaenia (Regan), captured at 14 different sampling points distributed in the floodplains of Chuí and São Miguel streams, near the road of Barra do Chuí. All ponds where annual fishes were recorded in Chuí were altered by some form of human activity, arising mainly from rice culture and trampling by cattle. The main area of annual fish occurrence in the municipality that is most relevant to conservation is located in the floodplain of the Chuí stream.

Key words: Austrolebias, conservation units, threatened fishes, wetlands 


\section{Introdução}

A partir da década de 1960, o governo brasileiro começou a incentivar amplamente o plantio de arroz irrigado em áreas úmidas como várzeas, banhados e pequenos charcos, no Estado do Rio Grande do Sul, através do programa federal Pró-Várzea. Com o crescimento da orizicultura no extremo sul do Brasil, aumentou também a superfície desses ambientes aquáticos afetados por obras de irrigação, canalização e drenagens, sem que houvesse qualquer planejamento paralelo visando à conservação de remanescentes de áreas úmidas (Fontana et al., 2003).

No Rio Grande do Sul, as áreas úmidas são consideradas o tipo de ambiente aquático mais ameaçado (Fontana et al., 2003). O cultivo de arroz realizado sem nenhuma forma de manejo ambiental ou respeito às Áreas de Preservação Permanente (APPs), geralmente em áreas baixas e planas, é um dos principais fatores responsáveis pela degradação e fragmentação desse tipo de ambiente (Reis et al., 2003). Embora não existam dados precisos, alguns pesquisadores estimam que na região sul do Brasil, cerca de $90 \%$ das áreas úmidas desapareceu no ultimo século (Maltchik et al., 2004; Guadagnin et al., 2005; Rolon e Maltchik, 2006; Stenert et al., 2008).

Os peixes anuais da família Rivulidae são especialmente afetados pela degradação e perda das áreas úmidas, por viverem exclusivamente neste tipo de ambiente. Cerca de $40 \%$ da ictiofauna ameaçada de extinção no Rio Grande do Sul pertencem a este grupo (Reis et al., 2003). Na família Rivulidae, a maioria das espécies é conhecida como peixe anual, por possuírem ciclo de vida curto, sendo encontrados na forma adulta em breves períodos do ano (Costa, 2002a). Como característica principal do grupo, os indivíduos depositam seus ovos no substrato e estes permanecem vivos durante períodos de seca em estágio de diapausa, aguardando a próxima estação chuvosa quando irão eclodir e iniciar um novo ciclo (Wourms, 1972).

No Rio Grande do Sul, 24 espécies de Rivulidae são registradas, destas 18 pertencem ao gênero Austrolebias (Costa, 2006; Ferrer et al., 2008), cinco a Cynopoecilus
(Costa, 2002b), e uma a Rivulus (Costa e Lanés, 2009). Apesar das eminentes ameaças antrópicas à maioria destas espécies, são raros trabalhos que enfoquem a distribuição e conservação deste grupo de peixes (Costa, 2002a; Reis et al., 2003; Volcan et al., 2009; Volcan et al., 2010a; 2010b). Deste modo, o presente estudo objetivou localizar e mapear as áreas de ocorrência dos rivulídeos no município do Chuí e verificar o estado de conservação das espécies amostradas.

\section{Material e Métodos}

\section{Área de estudo}

A planície costeira sul-rio-grandense, sul do Brasil, é considerada uma região de "extrema importância biológica" e uma das áreas prioritárias para conservação no país (MMA, 2000). Caracterizada por campos úmidos, alagados sazonalmente e permanentemente, campos secos, dunas e cordões litorâneos, onde o complexo lagunar Patos-Mirim é a feição dominante (Asmus, 1998), o que propicia, assim, uma paisagem diversificada e heterogênea.

Neste contexto, o município do Chuí apresenta $203 \mathrm{~km}^{2}$ e população de aproximadamente, cinco mil habitantes (IBGE, 2010). Seu território caracterizase por apresentar relevo predominantemente plano com cobertura vegetal de campos, coexistindo com atividade agropecuária, baseada no cultivo de grãos (principalmente arroz) e criação de gado.

\section{Amostragens}

Foram realizadas saídas de campo nos meses de agosto, setembro e outubro de 2004, julho, agosto e dezembro de 2005 e uma campanha em julho de 2009 , totalizando sete incursões a campo. As coletas foram efetuadas utilizando rede de arrasto pequena $(50 \times 150 \mathrm{~cm})$ e peneira $(60 \times 60 \mathrm{~cm})$ de malha tipo industrial $2 \mathrm{~mm}$. Os biótopos foram georeferenciados com GPS. Os peixes coletados foram fixados em formalina $10 \%$ no local da coleta e posteriormente conservados em álcool $70^{\circ} \mathrm{GL}$. Os espécimes foram identificados e medidos em seu comprimento padrão (em $\mathrm{mm}$ ). $\mathrm{O}$ material encontra-se depositado na 
Coleção Ictiológica Morevy Cheffe (CIMC) do Grupo Especial de proteção ao Ambiente Aquático do Rio Grande do Sul (GEEPAA-RS) constituindo material testemunho (Anexo 1).

\section{Resultados}

Foram registradas quatro espécies de peixes anuais (Figura 1) na área de estudo (Figura 2): Austrolebias charrua Costa e Cheffe, 2001; Austrolebias luteoflammulatus (Vaz-Ferreira, Sierra-de-Soriano e Scaglia-de-Paulete, 1964); Austrolebias prognathus (Amato, 1986) e Cynopoecilus melanotaenia (Regan, 1912), ocorrendo em 14 diferentes pontos de coleta. Em um ponto de coleta localizado na várzea do arroio Chuí, foram registradas as quatro espécies de Rivulidae ocorrendo sintópicas.

Conforme a Tabela 1, dentre as espécies registradas, a de maior abundância e distribuição no município foi $A$. charrua, representando $71 \%$ dos espécimes coletados, presente em 12 dos 14 pontos onde foram registrados rivulídeos. As populações estavam distribuídas na várzea dos arroios Chuí e São Miguel, em charcos marginais a BR 471 e da estrada da Barra do Chuí (Figura 2). Austrolebias luteoflammulatus foi encontrado em sete pontos de coleta, todos distribuídos nas várzeas dos arroios Chuí e São Miguel, e em charcos marginais à estrada da barra do Chuí, perfazendo 8,3\% dos indivíduos capturados. Austrolebias prognathus com 1,7\% dos indivíduos capturados foi a espécie de menor abundância e distribuição, ocorrendo de forma pontual em um charco localizado na várzea do arroio Chuí. Cynopoecilus melanotaenia foi registrada em três pontos de coleta, sendo dois na várzea do arroio Chuí e um na várzea do arroio São Miguel, representando $19 \%$ dos exemplares.

Os pontos amostrais estão inseridos em três áreas principais: estrada da Barra do Chuí, várzea do arroio Chuí e várzea do arroio São Miguel (Figura 2). Todas as áreas de ocorrência de peixes anuais apresentavam tamanho reduzido, em sua maioria com vegetação aquática abundante e completamente exposta à luz solar. A maioria dos ambientes apresentava substrato lodoso e geralmente muito pisoteado pelo gado, com profundidades máximas de $60 \mathrm{~cm}$.

TABELA 1: Lista das espécies, número de pontos de ocorrência $(\mathrm{P})$, contribuição percentual numérica (PN\%) e comprimento padrão de machos e fêmeas (CP em mm) das espécies de Rivulidae que ocorreram no município do Chuí, Rio Grande do Sul, Brasil.

\begin{tabular}{|c|c|c|c|c|}
\hline Espécie & $\mathbf{P}$ & $\begin{array}{l}\mathrm{PN} \\
\%\end{array}$ & $\mathbf{C P}$ & 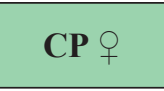 \\
\hline $\begin{array}{l}\text { Austrolebias charrua } \\
\text { Costa e Cheffe, } 2001\end{array}$ & 12 & 71 & $21,0-53,0$ & $18,5-43,5$ \\
\hline $\begin{array}{l}\text { Austrolebias luteoflam- } \\
\text { mulatus (Vaz-Ferreira, } \\
\text { Sierra-de-Soriano e } \\
\text { Scaglia-de-Paulete, } \\
\text { 1964) }\end{array}$ & 7 & 8 & $25,0-32,2$ & $20,0-30,5$ \\
\hline $\begin{array}{l}\text { Austrolebias progna- } \\
\text { thus (Amato, 1986) }\end{array}$ & 1 & 2 & $80,3-83,5$ & $87,2-104,0$ \\
\hline $\begin{array}{l}\text { Cynopoecilus melano- } \\
\text { taenia (Regan, 1912) }\end{array}$ & 3 & 19 & $19,0-33,5$ & $18,0-33,5$ \\
\hline
\end{tabular}

Dos 14 pontos onde foram capturados rivulídeos no Chuí, oito apresentavam peixes não anuais ocorrendo com os rivulídeos. Foram coletados 144 indivíduos de 11 espécies distintas, pertencentes a seis famílias e duas ordens. A ordem Characiformes foi predominante, com $73 \%$ das espécies, e a família Characidae foi a mais representativa, com $45 \%$ das espécies coletadas. As espécies não-anuais mais abundantes foram: Cnesterodon decemmaculatus, Astyanax cf. eigenmanniorum, Phalloceros caudimaculatus e Cheirodon interruptus, representando juntos $82 \%$ dos indivíduos coletados. Mimagoniates inequalis foi a espécie de menor abundância, com apenas um exemplar coletado. 


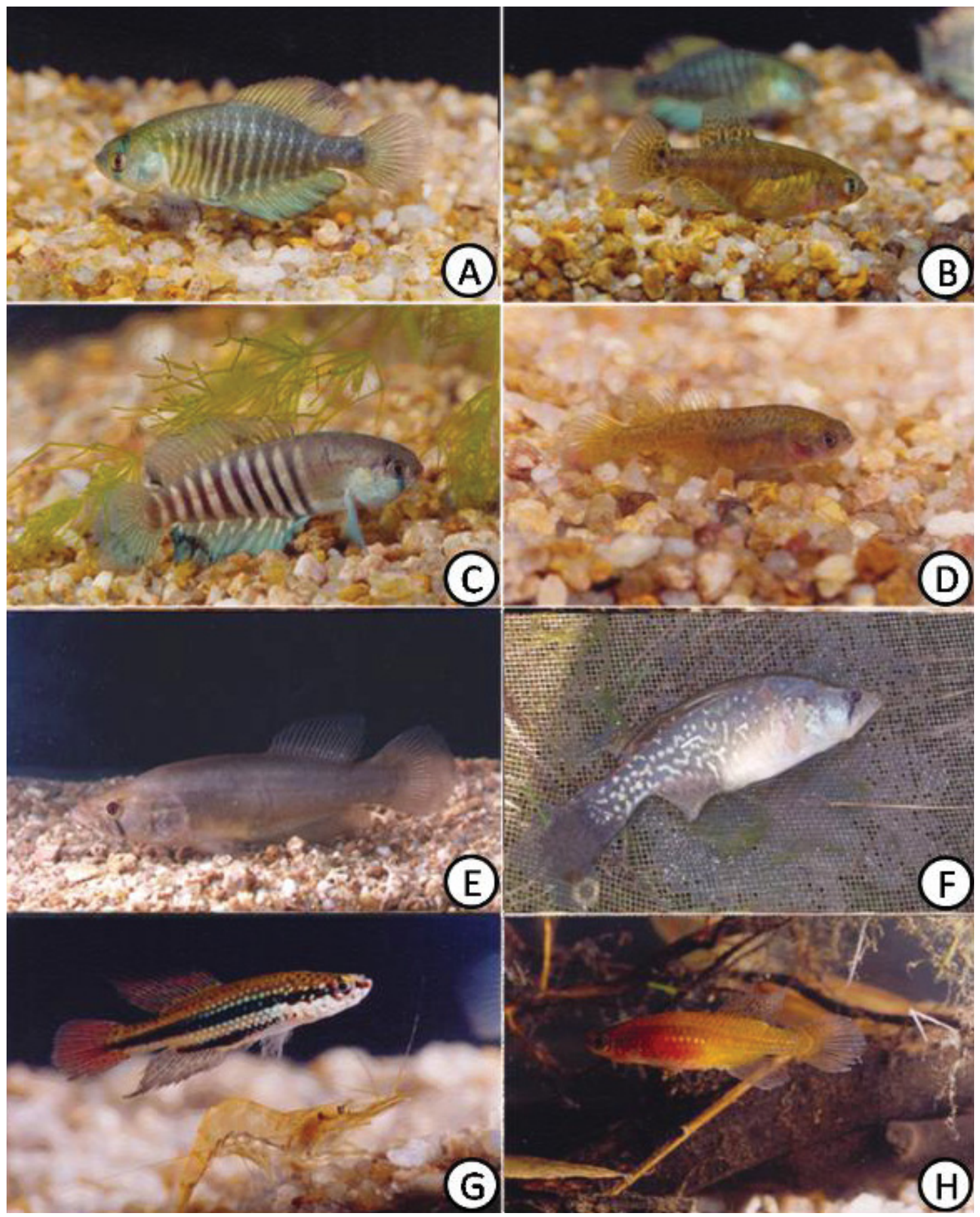

FIGURA 1: Peixes anuais, capturados no município do Chuí, extremo sul do Rio Grande do Sul, Brasil. A. Macho de A. charrua; B. Fêmea de A. charrua; C. Macho de A. luteoflammulatus; D. Fêmea de A. luteoflammulatus; E. Macho de A. prognathus; F. Fêmea de A. prognathus; G. Macho de C. melanotaenia; H. Fêmea de C. melanotaenia. Fotos de Norberto Jagaer e Matheus Volcan (Figura F). 


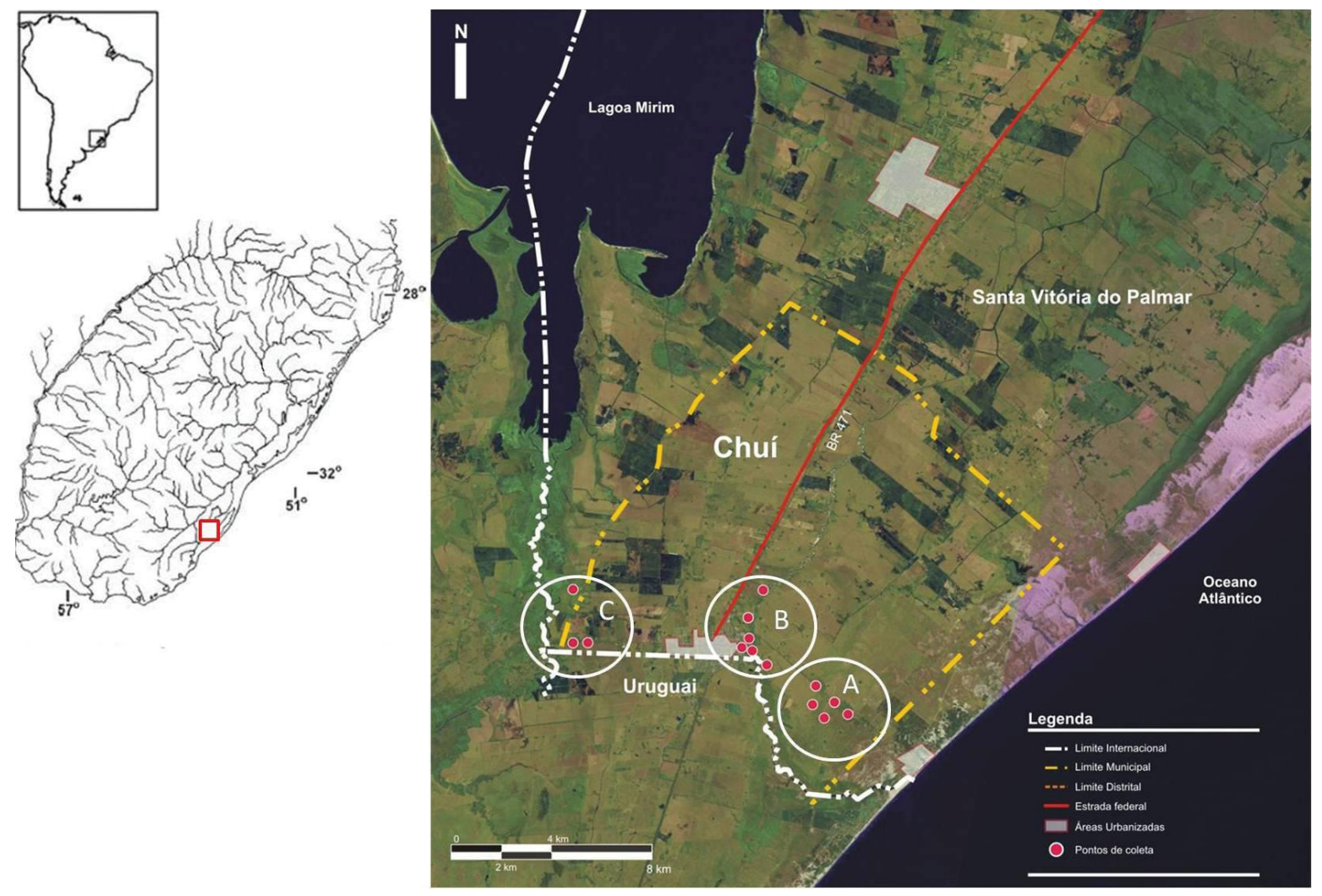

FIGURA 2: Pontos de coleta de peixes anuais no município do Chuí, estado do Rio Grande do Sul, Brasil. Estrada da Barra do Chuí (A), várzea do arroio Chuí (B) e Várzea do arroio São Miguel (C). Fonte: adaptado de Google Earth.

\section{Discussão}

Conforme Costa e Cheffe (2001) e Costa (2006), $A$. charrua se distribui desde a Planície Costeira adjacente à laguna Mirim ao norte do Departamento de Rocha no Uruguai até o município de Rio Grande, no distrito do Taim (comunicação pessoal). No município do Chuí, a espécie teve suas principais populações localizadas marginais à estrada da Barra do Chuí e nas várzeas dos arroios Chuí e São Miguel. Devido a pressão antrópica verificada em seu habitat e sua restrita área de distribuição, é listada como "Em Perigo" de extinção (Reis et al., 2003; Lima, 2008a).

Austrolebias luteoflammulatus se distribui ao longo de áreas baixas em drenagens associadas a sistemas da costa atlântica e drenagens da laguna Mirim no Brasil e Uruguai (Amato, 1986; D'Anatro e Loureiro, 2005; Costa, 2006). No Brasil, Costa (2002a) registrou a espécie apenas no município do Chuí em bordas de áreas úmidas temporárias extremamente rasas. A espécie é listada como "Vulnerável" no Rio Grande do Sul
(Reis et al., 2003) e Brasil (Lima, 2008b), apresentando distribuição marginal no município do Chuí.

Recentemente, em coletas realizadas no município de Santa Vitória do Palmar, duas populações de $A$. luteoflammulatus foram registradas, ampliando a sua distribuição no Brasil (Dados não publicados). A baixa plasticidade ecológica e à descaracterização e degradação de seu habitat ameaçam as populações remanescentes. Devido à pressão antrópica verificada nas áreas úmidas, recomenda-se que seja agravado o status de ameaça dessa espécie, visto que no Brasil $A$. luteoflammulatus tem ocorrência restrita ao extremo sul do Rio Grande do Sul, onde as populações são pouco abundantes.

De acordo com Amato (1986), A. prognathus era conhecida apenas para a bacia do arroio São Miguel e segundo Reichert et al. (1997) para a bacia do rio Cebollati, nas proximidades de Lascano no Uruguai. De acordo com Costa (2002a), era muito provável a ocorrência desta espécie no Brasil. Através da captura 
de quatro exemplares adultos durante o presente estudo, Costa (2006) confirma o registro desta espécie para a várzea do arroio Chuí no Brasil.

Apesar da intensiva busca por outras populações, apenas uma, com poucos exemplares de $A$. prognathus foi registrada, localizada na várzea do arroio Chuí, no perímetro urbano do município. Esta área úmida localizada marginal à estrada da Barra do Chuí (Figura 3) se encontra bastante descaracterizada pela pecuária e circundada por cultivos de arroz. Embora alterado, este local foi o único ponto amostral onde as quatro espécies ocorreram sintópicas. Em função da baixa densidade da espécie, seu registro pontual no Brasil e do avançado grau de degradação de seu habitat é recomendável que seja considerada "Criticamente Ameaçada" e incluída nas próximas listagens de fauna ameaçada de extinção.

Conforme Costa (2002b), C. melanotaenia, é uma espécie de ampla distribuição no sistema da laguna dos Patos, ao longo do canal São Gonçalo, lagoa Mirim e seus tributários no Brasil e Uruguai. Essa espécie, apesar de possuir a maior área de distribuição no Brasil entre as espécies capturadas no município, apresentou poucos registros no Chuí, tendo as principais populações localizadas nas várzeas do arroio Chuí. Não é considerada ameaçada de extinção no Rio Grande do Sul e Brasil.

O registro de espécies de peixes não anuais ocorrendo com os Rivulidae nas áreas úmidas amostradas no Chuí reforça o que foi constatado por Vaz-Ferreira et al. (1966) em áreas úmidas temporárias no Uruguai, de que esses ecossistemas, por muitas vezes estarem associados com planícies de inundação, conectam-se a massas de água perenes em determinados períodos do ano, permitindo a entrada de espécies de peixes alóctones, que buscam alimento e refúgio seguro de predadores.

Assim como verificado no Chuí, o pequeno porte das áreas úmidas foi registrado também por Maltchik et al. (2003), que inventariaram cerca de 3.500 áreas úmidas no Sul do Brasil e aproximadamente $70 \%$ delas possuíam tamanho inferior a $1 \mathrm{~km}^{2}$. Este padrão é consequência de uma severa fragmentação de habitat causada pela expansão agrícola, especialmente as plantações de arroz. É comum o aproveitamento das áreas de várzea para o cultivo do arroz no extremo sul do Rio Grande do Sul, o que torna essa cultura a maior ameaça para os peixes anuais dessa região (Costa, 2002a; Reis et al., 2003; Volcan et al., 2009; Volcan et al., 2010a; 2010b).

Segundo Maltchik et al. (2010), a maioria das áreas úmidas são fragmentadas e de pequeno porte, e apesar de apresentarem menor riqueza que áreas úmidas relativamente maiores, demonstram apresentar uma composição de espécies distinta, sugerindo que tanto áreas grandes quanto pequenas merecem atenção, principalmente em regiões onde a agricultura e o florestamento com espécies exóticas vem se expandindo.

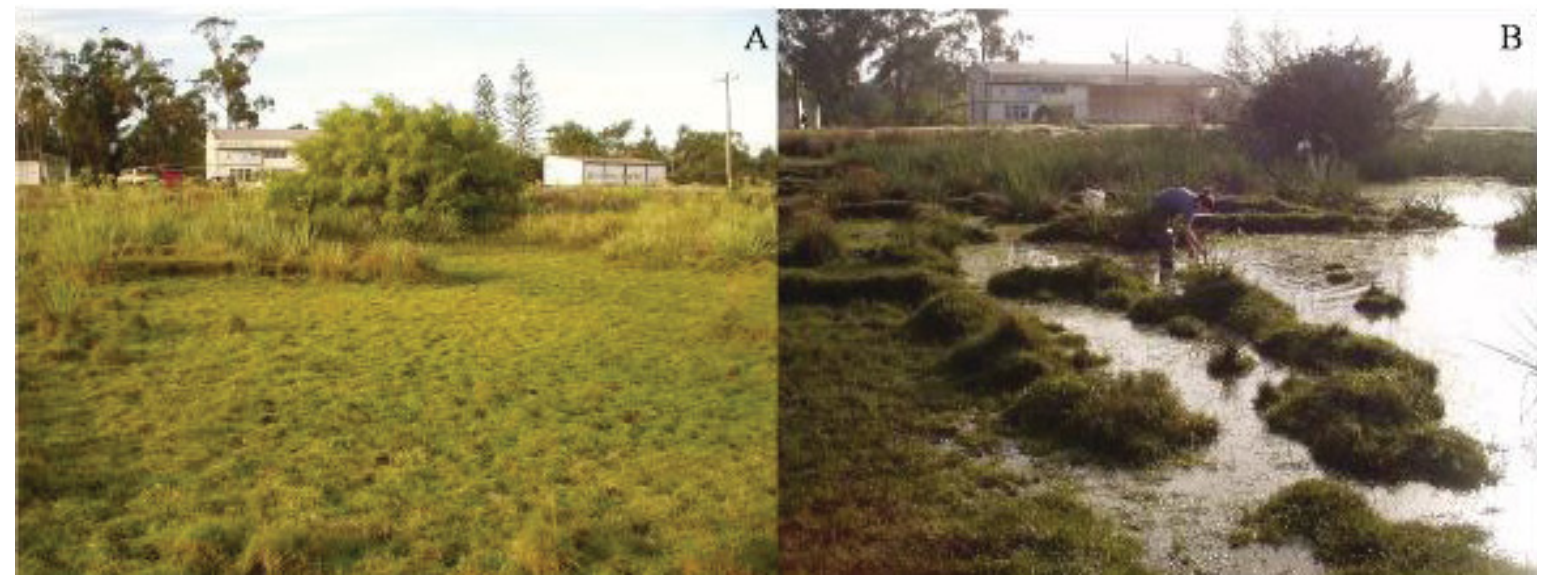

FIGURA 3: Ponto localizado na várzea do arroio Chuí, marginal à estrada da Barra do Chuí. Esta área foi à única onde se capturaram as quatro espécies de peixes anuais registradas no estudo ocorrendo juntas. Apesar da elevada riqueza, este ambiente encontrase sob forte atividade antrópica, como loteamentos, criação de gado e orizicultura. (A) Registro do ambiente completamente seco no verão de 2005; (B) Foto retirada em agosto de 2005, durante a estação de chuvas (inverno). Fotos de Matheus Volcan. 
Devido aos charcos e pequenos banhados estarem se tornando "ilhas" em meio à matriz de campo (geralmente substituídos pela cultura do arroz) e em sua maioria representarem uma pequena porção de área "improdutiva" dentro de propriedades particulares, uma maneira de tentar assegurar a conservação dos rivulídeos, no extremo sul do Rio Grande do Sul, seria o estímulo à criação de pequenas reservas particulares nas áreas com ocorrência de peixes anuais, onde o simples isolamento das pequenas áreas, impedindo a progressão da lavoura de arroz, auxiliaria na proteção desses suscetíveis ambientes. Entretanto, apenas essas medidas podem tornar essas populações isoladas. A fragmentação e perda de habitat impedem a conexão destas zonas úmidas habitadas por rivulídeos e a dispersão das espécies nas planícies de inundação. Assim, além da necessidade de proteger o seu restrito habitat, deve ser realizado também o estabelecimento e a criação de grandes áreas protegidas que abriguem populações de Rivulidae.

A maioria das populações de peixes anuais registradas no município do Chuí aparentemente está em declínio, e sofrem com diversas formas de impactos antrópicos, devido principalmente ao cultivo do arroz, o qual é feito sem que exista nenhum diagnóstico ambiental ou plano de manejo nas áreas de plantio. Além disso, outras atividades econômicas como o plantio do eucalipto, lavouras de soja, parques eólicos e barramentos de cursos d'água para irrigação, energia e aquacultura estão ganhando força na metade sul do Rio Grande do Sul e constituem novas ameaças para as populações locais, caso não se realize um correto licenciamento das áreas a serem utilizadas. Obras realizadas em rodovias, como duplicação e ampliação, devem respeitar também as áreas úmidas, de forma a evitar a supressão desses locais, uma vez que muitas populações são registradas marginais a estradas. Nesse sentido, o mapeamento das populações de peixes anuais é imprescindível para garantir a conservação das espécies.

Os resultados obtidos neste trabalho demonstram que a implantação de uma unidade de conservação que contemple o arroio Chuí e suas várzeas poderia assegurar a viabilidade e a conservação das principais populações de peixes anuais ocorrentes no município do Chuí.

\section{Agradecimentos}

A Nadna Vieira, Thedy Eni Vieira e Elon Vieira pelo apoio e incentivo a este estudo. A Alinca Fonseca, Michel Corrêa e Gustavo Wallwitz pelo auxílio nos trabalhos de campo. Ao professor Maximiano Cirne pelo apoio ao projeto. A Norberto Jaeger (in memoriam) pelas imagens dos peixes. Ao IBAMA/ICMBio pela licença de coleta (18334-1).

\section{Referências}

Amato, L. H. 1986. Seis espécies nuevas del genero Cynolebias Steindachner, 1876, de Uruguay y Paraguay (Cyprinodontiformes, Rivulidae). Comunicaciones Zoologicas del Museo de Historia Natural de Montevideo, 162:1-27.

Asmus, M. L. 1998. A Planície Costeira e a Lagoa dos Patos. In: Seeliger, U.; Odebrecht, C. \& Castello, J. P. (Orgs). Os Ecossistemas costeiros e marinhos do extremo sul do Brasil. Ed. Ecoscientia, Rio Grande, Brasil, p.7-12.

Costa, W. J. E. M. 2002a. Peixes anuais brasileiros: diversidade e conservação. Ed. UFPR, Curitiba, Brasil, 238pp.

Costa, W. J. E. M. 2002b. The anual fish genus Cynopoecilus (Cyprinodontiformes, Rivulidae): taxonomic revision, with descriptions of four new species. Ichthyological Exploration of Freshwaters, 13: 11-24.

Costa, W. J. E. M. 2006. The South American annual killifish genus Austrolebias (Teleostei:Cyprinodontiformes: Rivulidae): phylogenetic relationships, descriptive morphology and taxonomic revision. Zootaxa, 1213: 1-162.

Costa, W. J. E. M.; Cheffe, M. M. 2001. Three new annual fishes of the genus Austrolebias from the Laguna dos Patos system, southern Brazil and redescription of $A$. adloffi (Ahl) (Cyprinodontiformes: Rivulidae). Comunicação do Museu de Ciências e Tecnologia da PUCRS, Série Zoologia, 14 (2): 179-200.

Costa, W. J. E. M.; Lanés, L. E. K. 2009. Rivulus riograndensis, a new aplocheiloid killifish from southern Brazil (Cyprinodontiformes: Rivulidae). Ichthyological Exploration of Freshwaters, 20: 9195.

D'Anatro, A.; Loureiro, M. 2005. Geographic variation in Ausrolebias luteoflammulatus Vaz-Ferreira, Sierra e Scaglia (Cyprinodontiformes, Rivulidae). Journal of Fish Biology, 67: 849-865.

Ferrer, J.; Malabarba, L. R.; Costa, W. J. E. M. 2008. Austrolebias paucisquama (Cyprinodontiformes: Rivulidae), a new species of annual killifish from southern Brazil. Neotropical Ichthyology, 6 (2): 175-180.

Fontana, C. S.; Bencke, G. A.; Reis, R. E. 2003. Livro vermelho da fauna ameaçada de extinção no Rio Grande do Sul. Edipucrs, Porto Alegre, Brasil, 632pp.

Guadagnin, D. L.; Peter, A. S.; Perello, L. F. C.; Maltichik, L. 2005. Spatial and temporal patterns of waterbird assemblages in fragmented wetlands of southern Brazil. Waterbirds, 28 (3): 261272. 
IBGE - Instituto Brasileiro de Geografia e Estatística. 2010. Censo Demográfico - Cidades. Disponível em <http://www.ibge.gov.br/ cidadesat $>$. Acesso em 30 de março de 2010.

Lima, F. C. T. 2008a. Austrolebias charrua. In: Machado, A. B. M.; Drummond, G. M. \& Paglia, A. P. (Eds). Livro vermelho da fauna brasileira ameaçada de extinção. Ministério do Meio Ambiente, Brasília, Brasil, 278pp.

Lima, F. C. T. 2008b. Austrolebias luteoflammulatus. In: Machado, A. B. M.; Drummond, G. M. \& Paglia, A. P. (Eds.). Livro vermelho da fauna brasileira ameaçada de extinção. Ministério do Meio Ambiente, Brasília, Brasil, 278pp.

Maltchik, L.; Lanés, L. E. K.; Stenert, C; Medeiros, E. 2010. Speciesarea relationship and environmental predictors of fish communities in coastal freshwater wetlands of southern Brazil. Environmental Biology Fishes (DOI: 10.1007/s10641-010-9614-0).

Maltchik, L.; Rolon, A. S.; Guadagnin, D.; Stenert, C. 2004. Wetlands of the Rio Grande do Sul, Brazil: a classification with emphasis on their plant communities. Acta Limnologica Brasiliensis, 16 (2): 137-151.

Maltchik, L.; Schneider, E.; Becker G.; Escobar, A. 2003. Inventory of wetlands of Rio Grande do Sul (Brazil). Pesquisa Botânica, 53: 89-100.

MMA - Ministério do Meio Ambiente. 2000. Avaliação e ações prioritárias para a conservação da biodiversidade da Mata Atlântica e Campos Sulinos. MMA, Brasília, Brasil, 40pp.

Reichert, J. J.; Pietro, F.; Salvia, H. 1997. Facherfische aus Uruguay. DKG-Journal Supplemetheft, 5: 1-58.

Reis, R. E.; Lucena, Z. M.; Lucena, C. A. S.; Malabarba, L. R. 2003. Peixes. In: Fontana, C. S.; Bencke, G. A. \& Reis, R. E. (Orgs). Livro vermelho da fauna ameaçada de extinção no Rio Grande do Sul. Edipucrs, Porto Alegre, Brasil, 632pp.

Rolon, A. S.; Maltchik, L. 2006. Environmental factors as predictors of aquatic macrophyte richness and composition in wetlands of southern Brazil. Hidrobiologia, 556: 221-231.

Stenert, C. B.; Mostardeiro, C.; Maltchik, L. 2008. Environmental predictors of macroinvertebrate communities in coastal wetlands of southern Brazil. Marine and Freshwater Research, 59: 540-548.

Vaz-Ferreira, R.; Sierra de Soriano, B.; Señorans J. S. 1966. Integracion de la fauna de vertebrados em algunas masas de agua dulce temporales del Uruguay. Compendios de Trabajo del Departamento de Zoologia Vertebrados de la Facultad de Humanidades y Ciencias, 25: 1-16.

Volcan, M. V.; Lanés, L. E. K.; Gonçalves, A. C. 2009. Thereatened fishes of the world: Austroebias nigrofasciatus Costa and Cheffe, 2001 (Cyprinodontiformes, Rivulidae). Environmental Biology of Fishes, 86 (3): 443-444.

Volcan, M. V.; Lanés, L. E. K; Gonçalves, A. C. 2010a. Thereatened fishes of the world: Austroebias univentripinnis Costa and Cheffe, 2005 (Cyprinodontiformes, Rivulidae). Environmental Biology of Fishes, 87 (4): 319-320.

Volcan, M. V.; Lanés, L. E. K.; Gonçalves, A. C. 2010b. Pisces, Cyprinodontiformes, Rivulidae, Austrolebias periodicus (Costa, 1999): Distribution extension in state of Rio Grande do Sul, southern Brazil. Check List 6(2): 234-236.

Wourms, J. P. 1972. The development Biology of annual fishes III. Preembrionic and embrionic diapause variable duration in the eggs of the annual fishes. Journal of Experimental Zoology, 182: 389-414.

\section{Anexo 1: Material examinado}

Austrolebias charrua: CIMC 8895, 18 ex., charco marginal ao arroio Chuí a 100 metros da ponte da estrada da Barra do Chuí, 29-VIII-2004. CIMC 8905, 5 ex., charco marginal à estrada da Barra do Chuí, 29-VIII2004. CIMC 8908, 15 ex., charco marginal à estrada da Barra do Chuí, 29-VIII-2004. CIMC 8912, 18 ex., charco marginal à estrada da Barra do Chuí, 29-VIII2004. CIMC 8916, 28 ex., charco marginal à estrada da Barra do Chuí, 29-VIII-2004. CIMC 8920, 7 ex., mesmo local do lote CIMC 8895, 25-IX-2004. CIMC 8924, 15 ex., aproximadamente 100 metros de onde foi coletado o lote CIMC 8895, na várzea do arroio Chuí, 25-IX2004. CIMC 8938, 1ex., charco próximo à várzea do arroio Chuí, 25-IX-2004. CIMC 9481 - 10 ex., estrada marginal ao arroio São Miguel, 10-VII-2005. CIMC 9483 - 10 ex., estrada vicinal próxima à ponte do arroio Chuí, 10-VII-2005. CIMC 9485 - 10 ex., estrada da Barra do Chuí em frente à entrada da fazenda Charrua, 10-VII-2005. CIMC 9487 - 13 ex., várzea do arroio Chuí, 10-VII-2005.

Austrolebias luteoflammulatus: CIMC 8895 - 1 ex., charco marginal ao arroio Chuí, 29-VIII-2004. CIMC 8902 - 2 ex., charco marginal à estrada da Barra do Chuí, 29-VIII-2004. CIMC 8928 - 4 ex., charco marginal ao arroio Chuí, 25-IX-2004. CIMC 8942 - 5 ex., charco localizado na várzea do arroio Chuí, 25-IX-2004. CIMC 9482 - 1 ex., estrada marginal ao arroio São Miguel, 10VII-2005. CIMC 9507 - 2 ex., estrada vicinal próxima à ponte do arroio Chuí, 10-VII-2005. CIMC 9486-10 ex., estrada da Barra do Chuí em frente à entrada da fazenda Charrua, 10-VII-2005.

Austrolebias prognathus: CIMC 8586 - 3 ex., charco na várzea do arroio Chuí, 29-VIII-2004. CIMC 8626, 1 ex., coletado no mesmo local do lote CIMC 8593, 25-IX-2004.

Cynopoecilus melanotaenia: CIMC 8899-35 ex., charco marginal ao arroio Chuí, 29-VIII-2004. CIMC 8933 - 19 ex., charco localizado na várzea do arroio Chuí, 25-IX-2004. CIMC 8936 - 6 ex., charco marginal ao arroio São Miguel, 25-IX-2004. CIMC 9488 - 12 ex., várzea do arroio Chuí, 10-VII-2005. 